\title{
MANUEL PARDO DE ANDRADE Y SU «SEMANARIO POLÍTICO»
}

\author{
por \\ MARÍA ROSA SAURIN DE LA IGLESIA
}

En agosto de 1809, a los dos meses de ser expulsados los franceses de Galicia gracias al esfuerzo conjunto del ejército y la población civil, salía de la imprenta coruñesa de Francisco Cándido Pérez Prieto un periódico de pequeño formato y grandes propósitos: el «Semanario Político, Histórico y Literario de La Coruña». Recién conseguida la retirada del enemigo se hacía sentir pesadamente sobre el país el aislamiento derivado de su posición geográfica y agravado por la guerra así que la aparición de un órgano local de información tuvo que ser saludada con albricias por un público sediento de noticias y de orientación. No iba a ser, sin embargo, la noticia menuda, en su escueta simplicidad, el objeto principal de esta publicación, como se deducía de sus enjundiosas veinticinco páginas. Lo que predomina en ellas es la reflexión acerca de los grandes problemas de una coyuntura de suyo inquietante $y$, en ese sentido, la extensión y profundidad de sus artículos eran ya promesa del empeño con que se habían de abordar allí las cuestiones doctrinales. Eso explica la razón de su periodicidad semanal. Todo en el nuevo periódico apuntaba no tanto a celebrar la victoria como a aprovechar el entusiasmo de la primera hora para crear un estado de ánimo compacto contra la presencia francesa en España, postura resuelta y bien diversa de la que inspiraba a los altos cargos militares, tendentes, por lo que se sabe, a neutralizar los logros de las juntas populares ${ }^{1}$.

${ }^{1}$ Cfr. Conde de TORENO, Historia del levantamiento, guerra y revolución de España, B.A.E., Madrid, 1953, p. 197a.

"CUADERNOS DE ESTUDIOS GALLEGOS", Tomo XLII, Fascículo 107, Santiago 1995. 
Como punto de partida y lema del periódico destaca la alusión a la errada política de los últimos tiempos, resumida de manera muy sugerente en la portada con el horaciano Quidquid delirant reges, plectuntur Achivi. Con esta sentencia se venía a corroborar la impresión, corriente desde la subida de Godoy al poder, de que los males de España se habían generado muy cerca del trono. La división del «Semanario» en tres secciones - política, histórica y literaria-, además de dar variedad a su contenido, permitía abordar desde diferentes enfoques cuestiones de la más candente actualidad. E incluida entre ellas, como se verá luego, la de la creación literaria.

Nada en los primeros números - a excepción de unas iniciales al pie de una poesía - indicaba a quién atribuir la nueva publicación aunque eso no debía ser ningún misterio en la pequeña ciudad atlántica, donde todos se conocían y cuyos intelectuales formaban un círculo compacto. Pero, en el $\mathrm{n}^{\circ}$ 3, la firma de Manuel Pardo de Andrade acababa de aclarar las cosas presentándose como editor responsable y «español rancio», en total desacuerdo con las directivas del poder francés. Ese nombre era bien conocido de los contemporáneos y su mayor garantía de seriedad era haber tenido a su cargo la redacción del «Diario de La Coruña» desde el 22 de junio de 1808 hasta el momento de la invasión. En el momento de salir el nuevo «Semanario», el escritor se hallaba en la plena sazón de sus cuarenta y ocho años, contaba con un historial académico muy sólido y tenía además en su haber otras experiencias publicísticas estimables, añadiendo con todo ello al renombre del solar de añeja hidalguía en que había nacido su propia fama de hombre de letras, poeta y philosophe conocido y apreciado de sus conciudadanos ${ }^{2}$. Esta nueva aparición en público, precisamente en un momento como aquél de desorientación de la sociedad, de absoluta crisis del estado y de catástrofe económica completa se demostrará decisiva por representar el primer intento realizado en Galicia - y quizá también en España - de dar voz a un grupo social hasta allí silencioso si bien importante y activo, esto es, el de la burguesía de negocios, espina dorsal de la economía local. En el estado actual de la investigación faltan documentos que acrediten hasta qué punto pudo contar el «Semanario» con el respaldo económico de esa oligarquía gallega aunque consta, en cambio, el amplio

\footnotetext{
${ }^{2}$ Para más detalles sobre su biografía cfr. M.R. SAURIN DE LA IGLESIA, Manuel Pardo de Andrade y la crisis de la Ilustración, Gaesa, La Coruña, 1991.
}

"CUADERNOS DE ESTUdiOS GALlEGOS", Tomo XLII, Fascículo 107, Santiago 1995. 
consenso a que debía su existencia. Es el redactor mismo quien alude explicitamente a la confianza depositada en su persona por el público «que con instancias me rogó que escribiera y trabajara en beneficio de la patria [...]; y a la particular distinción con que me honró el Real Acuerdo de esta Audiencia en el informe que se le pidió para darme permiso de establecer este papel» ${ }^{3}$. Así pues, el «Semanario», que surgía con el beneplácito de los grupos de poder más avanzados de una ciudad comercial, debe ser reflejo claro de su ideología. Para situarlo mejor convendrá recordar la ambigüedad del panorama político del momento y, sobre todo, los contrastes entre juntas populares y autoridad militar que hacían peligrar el triunfo recién obtenido ${ }^{4}$. La principal novedad y atractivo del periódico estriba en su apoyo incondicional a la línea de conducta revolucionaria de las juntas locales, amenazada por el colaboracionismo de las altas esferas. Con ello se prentendía contrarrestar la tendencia que había conducido a estipular el reconocimiento explícito del rey José en las capitulaciones de La Coruña y Ferrol $^{5}$, con escándalo de España entera y reprobación de la Junta Central.

Fuente inestimable para la historia de aquellos asendereados días, estas páginas retratan además de cuerpo entero a su autor como experto publicista. Para la posteridad son informe y reflejo a un tiempo del temple de una sociedad y del modo de pensar del redactor, mientras que para los contemporáneos debieron representar el manifiesto de una ideología dispuesta a dar la batalla por el poder amén de un instrumento de comunicación ágil y abierto a la opinión de los lectores.

\section{EL PROTAGONISMO DE LA CORUÑA}

La excepcional gravedad de las circunstancias brindaba a Pardo de Andrade la oportunidad de erigirse en guía y mentor de sus conciudadanos, como representante de una mentalidad ciertamente minoritaria todavía pero tan constructiva y prometedora como para que su debilitamiento o desaparición mereciesen ser conjurados por cualquier medio.Ese peligro existía y se había impuesto a la atención general. No hay que olvidar que

\footnotetext{
${ }^{3}$ SPHLC, $n^{\circ} 20$, p. 460.

${ }^{4}$ TORENO, op. cit., p. 197a.

${ }^{5}$ Ibid., p. 159 b.
}

"CUADERNOS DE ESTUDIOS GALLEGOS", Tomo XLII, Fascículo 107, Santiago 1995. 
desde hacía medio siglo la fachada costera de Galicia venía experimentando un proceso creciente de desarrollo condicionado por la coyuntura internacional, ni que la duración de la paz entre las potencias había sido el caldo de cultivo ideal para que prendiese en todo el Reino un modernísimo concepto de capitalismo ${ }^{6}$. Esa favorable coyuntura, reforzada por una legislación previdente, había ensanchado tos horizontes de los pueblos costeros con las nuevas perspectivas del tráfico marítimo, favoreciendo con su despegue al hinterland. La considerable afluencia de capitales y de hombres de empresa foráneos logró así inyectar energías en un país hasta allí vinculado a un arcaísmo económico con resabios feudales, sin que el choque con la natural resistencia a cambiar consiguiera frenar su triunfo final. En su carrera ascendente, La Coruña se mostraba abocada a un protagonismo indiscutible entre los puertos que por entonces hicieron del comercio su razón vital: así es como aquel promontorio batido de los vientos, que hasta mediados del siglo XVIII había vivido unicamente en función de la Audiencia, se transformó en cuartel general de hombres de empresa prácticos y arrojados, españoles y extranjeros, que el Estado favorecía por considerarlos pilares insustituibles del bien común. El pulso perezoso de un mundo de leguleyos y funcionarios se aceleró, adaptándose al ritmo más enérgico del tráfico y los negocios marítimos. Pero, en la encrucijada de los siglos XVIII y XIX, la alteración de las relaciones internacionales dio al traste con toda aquella prosperidad para dejar paso a la guerra. $Y$ con ella se instauraron de manera estable - en lugar del progreso agrícola e industrial previsto para alimentar indefinidamente el tráfico con las Indias- las consecuencias más obvias de la nueva situación, esto es, el estancamiento del comercio y de las actividades industriales, el paro portuario y la quiebra de empresas, la falta de numerario y el empobrecimiento general. La crisis puso de manifiesto la urgencia de una revisión a fondo de la política seguida hasta el momento ${ }^{7}$ pero sólo el vuelco general desencadenado por la guerra contra Napoleon permitió abordar con visos de éxito el deseado

${ }^{6} \mathrm{Cfr}$. Luis ALONSO ALVAREZ, Industrialización y conflictos sociales en la Galicia del Antiguo Régimen (1750-1830), Akal, Madrid, 1976; id., Comercio colonial y crisis del Antiguo Régimen en Galicia (1778-1818), Xunta de Galicia, La Coruña, 1986; Joam CARMONA BADÍA, El atraso industrial de Galicia. Auge y liquidación de las manufacturas textiles (1750-1900), Ariel, Barcelona, 1990, pp. 168-170.

${ }^{7}$ Cfr. Emilio LA PARRA LOPEZ, La alianza de Godoy con los revolucionarios. (España y Francia a fines del siglo XVIII), C.S.I.C., Madrid, 1992.

"CUADERNOS DE ESTUDIOS GALLEGOS", Tomo XLII, Fascículo 107, Santiago 1995. 
reajuste de la vida colectiva. Lo importante era plantearlo en vista de los intereses de aquellos grupos sociales cuyo predominio, propiciado por el Antiguo Régimen, se tambaleaba ahora. Persuadidos de su función rectora, indiscutible en el ámbito económico, esos grupos de poder van a intentar apoderarse de los resortes del Estado para, desde allí, dar al futuro de los españoles una perspectiva política por completo nueva.

En Galicia, el compás de espera representado por la retirada del enemigo permitía reflexionar sobre el rumbo a seguir, que no podía ser sino la elaboración ulterior del programa ilustrado, de eficacia ya experimentada para remozar al país de su lastre arcaico. La herencia de las Luces, enriquecida y llevada a sus últimas consecuencias por la experiencia revolucionaria francesa, es el trasfondo con el que hay que contar para comprender el auge y la decidida voluntad de triunfo de la burguesía, tal como se manifiesta en el «Semanario Político». Su redactor, educado en la ideología ilustrada, había venido ensalzando desde sus primeras experiencias publicísticas la feliz concordia entre el Estado y los ciudadanos útiles como medio infalible de rescate y modernización para España entera.Y esa misma convicción había echado raíces en el ambiente corunés, por más que rara vez llegase a condensarse a nivel teórico. Como excepción que confirma la regla e indicio seguro del triunfo de aquella mentalidad ha de considerarse la traducción del archifamoso tratado Del commercio, del banquero pontificio Girolamo Belloni, que ve la luz en castellano en 1788, precisamente como reflejo de los intereses dominantes en el ambiente del Consulado de La Coruña ${ }^{8}$. No es ninguna casualidad que su traductor, José Lucas Labrada, secretario del Consulado, procediese de aquel mundo de hombres de acción que, como el mismo Belloni, veían en su colaboración con el poder el instrumento insustituible para desarrollar una sociedad retrasada. Precisamente ese mensaje, implícito en la obra de Belloni, es lo que explica su validez en los círculos mercantiles de La Coruña, todavía a los cincuenta años de su originaria aparición. Las particulares condiciones del Reino de Galicia permitían que aquella obra, nacida en el corazón del estado teocrático romano, pudiera seguir siendo interpretada como mani-

\footnotetext{
${ }^{8}$ Disertación sobre la naturaleza y utilidades del comercio: escrita en italiano por el Marqués Belloni, cambista romano, traducida al francés, y de éste al castellano, por D. Josef Lucas Labrada..., Aguayo, Santiago, 178; v. Alberto CARACCIOLO, Girolamo Belloni. Nota introduttiva, en Politici ed economisti del primo Settecento. Dal Muratori al Cesarotti, R. Ricciardi, Milano-Napoli, 1978, pp. 643-652.
}

"CUADERNOS DE ESTUDIOS GALLEGOS", Tomo XLII, Fascículo 107, Santiago 1995. 
fiesto de la reforma general apetecida por el sector «útil» de la sociedad. Es, pues, en el ambiente pragmático de la burguesía de negocios, reacia a perder la alianza con el gobierno de que había venido disfrutando en el Antiguo Régimen, donde se abre camino la consideración del Estado como un todo con los intereses de los súbditos, con manifestaciones como la protección de las manufacturas nacionales y el prohibicionismo en las fronteras. La participación de Pardo de Andrade en esa manera de pensar se puede comprobar desde sus intervenciones en el «Diario de Madrid», donde sus artículos subrayaban con calor cualquier inicitiva que en el comercio o la actividad industrial contribuyese, junto con las tradicionales actividades agrícolas, a la creación de riqueza ${ }^{9}$. Ya en aquellos escritos se trasluce una gran fe en la reorganización racionalista de España entera según los criterios triunfantes en Galicia por obra de los empresarios catalanes, criterios que no eran sino los del capitalismo liberal de estricta observancia y que, aplicados al sector pesquero, estaban transformándolo de raíz. Esa convicción no hará sino reforzarse con el paso del tiempo. Para todos los que pensaban como él, sólo la concordia entre el poder político y las fuerzas productivas podía garantizar la superación del colapso que atenazaba a España desde fines del siglo XVIII.

El curso de esas ideas, impedido a su debido tiempo en la expresión pública que el escritor de Jaz intentaba darle ${ }^{10}$, iba a desarrollarse ya sin cortapisas al quedar Galicia libre de franceses y dueña de sus destinos. La insospechada oportunidad que el vacío de poder brinda entonces al país para reorganizarse de arriba abajo es aprovechada sin tardanza por las capas sociales que a su fuerza económica pretendían ponerle el broche de oro del poderío político. Ese es el signo bajo el que nace el «Semanario Político» y que inspira el comportamiento no sólo de su redactor sino también de su entorno familiar y de una parte notable de la sociedad local. A través de la actitud de los Pardo de Andrade resulta muy interesante comprobar la penetración de la ideología del provecho entre la hidalguía rural.

\footnotetext{
${ }^{9} \mathrm{C}$ fr. Manuel PARDO DE ANDRADE, Los artículos del «Diario de Madrid» (17941800), edición e introducción de M. R. Saurin de la Iglesia, Fundación Barrié de la Maza, La Coruña, 1989.

${ }^{10}$ Sobre la fallida creación del periódico «El Curioso Herculino» v. Antonio MEIJIDE PARDO, Pardo de Andrade, devanceiro do xornalismo galego, en «Grial», abril-maioxunio 1983, n $^{\circ} 80$, pp. 159-162, y SAURIN DE LA IGLESIA, M. Pardo de Andrade..., cit., pp. 75-80.
}

"CUADERNOS DE ESTUdIOS GALLEGOS", Tomo XLII, Fascículo 107, Santiago 1995. 
Queda constancia, por ejemplo, de la libertad de espíritu con que el viejo Don Manuel, padre del escritor, sabía desentenderse de rancios prejuicios sociales para practicar actividades financieras tan fructíferas como la contrata de impuestos municipales; igualmente expresiva es la actitud del hermano mayorazgo al afrontar cuestiones prácticas de economía rural y, ante todo, la soltura con que actúa al arrinconar viejos contratos forales sustituyéndolos por arrendamientos, muchos más provechosos ${ }^{11}$. Síntoma de esta modernidad es también el que su nombre figure entre los matriculados en el Consulado, donde junto con tantos otros hidalgos y títulos de Castilla, dueños de importantes posesiones, aparece encuadrado al lado de armadores y mercaderes en una institución que dirigía la vida mercantil de la región. No hay que olvidar los fuertes intereses que ligaban a buena parte de la hidalguía local al trafico colonial con toda una variedad de aspectos hoy poco conocida: muchos de sus miembros, primeramente activos en Indias como «oficiales del Rey», conservaban de su actuación en tierras de ultramar relaciones comerciales importantes. Otros, sin moverse del país, jugaban con mayor o menor éxito la carta de la industria, ya fuera en lo textil o en las «ferrerías», y todos ellos, en su papel de productores de bienes de consumo y exportación, tendían a coaligarse con los profesionales de las finanzas y de la distribución comercial para favorecer la saca de sus producciones.

\section{LA RECONSTITUCIÓN DE UN IMPERIO ULTRAMARINO}

Se comprende que esta oligarquía bien afirmada añorase los tiempos en que el imperialismo francés no había trastornado todavía el equilibrio europeo. Los delicados frutos de la paz, perfectamente maduros antes del cataclismo revolucionario, merecían el elogio encendido de esos grupos que contribuían con su actividad cotidiana, sin alharacas pero también sin tregua, a las glorias de la civilización europea ${ }^{12}$. En ese ambiente es bien explicable la condena del imperialismo francés, destructor del equilibrio económico universal, no menos que la nostalgia de la hegemonía española

\footnotetext{
${ }^{11}$ Cfr. SAURIN DE LA IGLESIA, M. Pardo de Andrade..., cit., p. 52 y 90-92; y Archivo de la Real Sociedad Económica Matritense de Amigos del País, leg. 3357, y Archivo Histórico Nacional, Consejos, Leg. 1578.

${ }^{12}$ SPHLC, $\mathrm{n}^{\mathrm{0}} 12$, pp. $265-271 \mathrm{y} \mathrm{n}^{\circ} 41$, pp. 964-968.
}

"CUADERnOS DE ESTUdiOS GALLEGOS", Tomo XLII, Fascículo 107, Santiago 1995. 
que, en tiempos todavía tan próximos como los de Carlos III, disponía de espléndidos derroteros para el tráfico marítimo. Ecos de esa actitud se encuentran en el «Semanario Político», en cuyas páginas se plasma toda una teoría de la comunidad hispanoamericana en un momento en que el descrédito de España como gran potencia todavía no es completo. Por medio del «Semanario» Pardo de Andrade propone un modelo de desarrollo presidido a partes iguales por el prestigio del imperio carlotercista ${ }^{13}$ y por la admiración hacia el ejemplo inglés y destinado a restablecer cuanto antes el comercio ultramarino en su anterior prosperidad. La anglofilia de Pardo de Andrade es explícita y su admiración hacia la Gran Bretaña comprensible si se tiene en cuenta ya simplemente cómo había abordado ese país su modernización social, política y económica, evitando al país traumas sangrientos ${ }^{14}$. Con la amistad del cónsul Jardine, ilustrado y jacobino, hubieron de reforzarse en el escritor de Jaz no pocas de esas ideas y con ellas el aprecio hacia la sensata flexibilidad británica. Esa actitud es constante en sus escritos y cede sólo ante razones de fuerza mayor, como la conservación de la paz, cada vez que la prepotencia marítima de Inglaterra la hacía peligrar. Será ése el tema que inspire algunas de sus composiciones poéticas: un soneto no datado pero fácil de colocar historicamente ${ }^{15}, \mathrm{y}$ los poemas heroicos La Herculana y Derrota de los ingleses en Buenos Aires.

El resurgimiento económico que Pardo de Andrade considera deseable se basa precisamente sobre aquella libre solidaridad entre las dos orillas del Atlántico que, cuando estaba vigente la «sabia constitución antigua», había dado tiempos felices al comercio de Cádiz y La Coruña ${ }^{16}$. Un cierta idealización de ese pasado feliz lo lleva a ensalzar los logros del pasado sugiriéndole la búsqueda de soluciones políticas que, como entonces, supiesen respetar los intereses colectivos. Una de las principales habría de ser la igualdad con los criollos, base desde la que replantear una relación comercial de nuevo cuño ${ }^{17}$. Desde esa perspectiva se comprende todo el

\footnotetext{
${ }^{13}$ Cfr. José María JOVER ZAMORA, España en la transición del siglo XVIII al XIX, en Política, diplomacia y humanismo popular, Turner, Madrid, 1976, p. 201.

${ }^{14}$ Cfr. Josep FONTANA, La quiebra de la monarquía absoluta. 1814-1820, Ariel, Barcelona, 1971, pp. 30-37.

${ }^{15}$ SAURIN DE LA IGLESIA, M. Pardo de Andrade..., cit., p. 353.

${ }^{16}$ SPHLC, ${ }^{\circ} 10$, pp. 220-221.

${ }^{17}$ ALONSO ALVAREZ, Comercio..., cit., p. 238.
}

"CUADERNOS DE ESTUdiOS GALLEGOS", Tomo XLII, Fascículo 107, Santiago 1995. 
alcance de la reforma que el escritor de Jaz tiene ahora ocasión de enunciar en toda su amplitud aunque viniera meditándola desde los tiempos del «Diario de Madrid»: se trataba de constituir una estrato social de suficiente amplitud como para respaldar la gran aspiración liberal de un reajuste político y económico radical. Evidenciar el peso de los ciudadanos útiles sería más fácil cuando al lado del capitalista figurasen también sus asalariados, en una simbiosis favorecida por el gusto al trabajo y la circulación de numerario. He aquí a dónde venía a dar la tan traída y llevada polémica sobre el lujo: sólo cuando la educación generalizada y la elevación del nivel de vida hubiesen dignificado a una población de pobres y vagabundos, podría España medirse con los países civilizados, y sus habitantes - al igual que los ingleses - considerar como cosa propia el Estado que tal situación garantizase. Al sentar la exigencia de una base común a todos los habitantes del país Pardo de Andrade demuestra haber asimilado los ideales igualitarios del momento, colocándose a la vanguardia del pensamiento político de su tiempo.

La urgencia de esa meta y la falta de medios adecuados para improvisar una cultura política generalizada es lo que da a la prensa un papel de primer orden ya que por medio de ella podían aprender «los pueblos que deben respetar y obedecer las autoridades [...]; conocer que no son esclavos [...]; saber las gracias que les debe dispensar el gobierno y las obligaciones de cada individuo en su clase [...]; desterrar el ocio [...]; y [hacer] que la nación vuelva al renombre y gloria que tuvo en los pasados siglos» ${ }^{18}$. En esa concienciación de urgencia que, dando al «pueblo» conciencia de su propia dignidad le brindaba el acceso a un protagonismo renovador, una enorme responsabilidad se les asigna a «los que se precian de patriotas, los Padres de la Patria, Doctores y Curas, cuyo ministerio es instruir y orientar al público de sus obligaciones civiles, religiosas y sagradas ${ }^{19}$. Los acontecimientos se encargarían de demostrar sin tardanza la insolidaridad de esos privilegiados con cualquier innovación de signo radical.

Con su típico estilo asistemático Pardo de Andrade insistirá repetidamente sobre los medios de hacer madurar una conciencia política generalizada. Más que en discursos teóricos confía en el poder cohesivo de empre-

\footnotetext{
${ }^{18}$ SPHLC, $\mathrm{n}^{\circ} 49$, pp. 1157-1158.

${ }^{19}$ SPHLC, $\mathrm{n}^{\circ} 49$, p. 1115.
}

"CUADERNOS DE ESTUDIOS GALLEGOS", Tomo XLII, Fascículo 107, Santiago 1995. 
sas de interés colectivo y por eso lanza desde el periódico proyectos de acción conjunta con que salir de la inercia. Muy convincente es el de colaboración hispanoamericana, talismán para acceder a un nuevo avatar del imperio colonial español que, con la reconversión del sistema de tráfico interoceánico, inauguraría una era de bienestar. Aquí radica la importancia del artículo con que el $\mathrm{n}^{\circ} 13 \mathrm{del}$ «Semanario» sorprendía a sus lectores, anticipando ideas que se consolidarán más tarde, en la redacción definitiva de $1811^{20}$. En este primer avance de su pensamiento la gran novedad está en saber trazar, tras añosas disquisiciones acerca de la irrefrenable decadencia española, la imagen optimista de un futuro fascinante abierto a todos los españoles. Con prudencia suficiente para atraer en primer lugar a las clases propietarias pero sin enajenarse a las demás, se anuncia aquí una combinación insospechada de igualdad de oportunidades y bienestar social, oferta con la que la burguesía de negocios intenta ganarse el interés de los desposeídos y acallar antiguas tensiones sociales. El escritor tiene buen cuidado de proclamar al mismo tiempo el protagonismo de las clases poseedoras vinculándolo al libre uso de su propiedad y haciéndolo incompatible, por tanto, con supervivencias feudales. Para más, sin negar la importancia de la aristocracia, le fija deberes precisos, de manera «que sean útiles los nobles a la patria, y que acrediten ya en las armas, ya en las letras $\mathrm{y}$ en todas sus acciones la distinción que merecen». Libertad plena en los negocios y moralidad estricta en la conducta son las coordenadas generales dentro de las que se encuadra esta visión liberal de la nueva sociedad española. Con un enfoque cuyo referente más aproximado es el moderno Welfare State, Pardo de Andrade despliega aquí un atractivo programa, destinado a poner al alcance de la mano la tan traída y llevada «felicidad pública», vaga expresión siempre en candelero en el último medio siglo y por fin traducida ahora en términos tan concretos como la posibilidad de acceso a un nivel de vida superior para la mayoría de la población. Todo ello habría de venir de la mano de una serie de reformas políticas profundas, correspondientes al catálogo de desiderata del mejor dirigismo ilustrado. Una vez regenerados los españoles por una legislación sabia y previdente —obra, por supuesto, de la oligarquía «útil»—, persuadidos de su igualdad, educados en un cristianismo auténtico, alfabetizados, y, des-

${ }^{20}$ Manuel PARDO DE ANDRADE, Reflexiones sobre la mejor Constitución posible de España, Vila, La Coruña, 1811.

"CUADERNOS DE ESTUdiOS GALLEGOS", Tomo XLII, Fascículo 107, Santiago 1995. 
de luego, bien alimentados, no podrían dejar de identificarse con el gobierno que tal situación supiese garantizar. La imagen de España así originada, en abierto contraste con los lugares comunes, se encargaría de demoler prejuicios haciendo ver

«que los españoles han dexado de dormir y vagar por las plazas y calles ociosos, envueltos en cinco varas de paño; que así el rico como el pobre ocupan el tiempo en adquirir éste medios licitos con que subsistir; y el señor en servir a la patria» ${ }^{21}$.

Sobre tan atractivo programa el escritor retorna con gusto, perfilando su pensamiento en varias ocasiones más, con detalles reveladores. De ellos se desprende lo mucho que había meditado la cuestión, con todo su entramado de consecuencias sociales y económicas. Así se comprueba en las observaciones del $\mathrm{n}^{\circ} 42$ sobre la inminente grandeza a que estaba abocada España por obra y gracia de la revolución en acto. De considerar la superioridad geofísica de los territorios del imperio hispánico - «la primera potencia del mundo en riqueza y posesiones» - a encarecer las ventajas incalculables para todos sus habitantes no hay sino un paso. Como Adam Smith, Pardo de Andrade está convencido del progreso natural de la opulencia y de la milagrosa regeneración de España entera cuando se hubiese conseguido la convergencia de agricultura, industria y comercio. ¿Utopía? ¿Proyectismo innocuo? Más bien se diría confianza en la iniciativa, hasta allí insuperable, de la burguesía ascendente y, por supuesto, en el admirado modelo colonial inglés. La referencia explícita a la igualdad entre españoles y criollos añadía un atractivo más a ese plan de concordia y prosperidad, uno más entre los incomparables resultados de la consecución del estado de derecho ${ }^{22}$.

\section{LOS PLANES DEL REFORMADOR SOCIAL}

Alcanzar esa meta suponía la consolidación previa en todos los niveles de la sociedad de valores tipicamente burgueses tales como el amor al trabajo y el espíritu de lucro, desconocidos de las clases que una tradición

\footnotetext{
${ }^{21}$ SPHLC, $n^{\circ} 42$, p. 995
}

${ }^{22}$ SPHLC, no 36 , p. 848. 
secular había acostumbrado a vivir de limosna. Al Estado competía mejorar sus condiciones de existencia para transformar de raíz sus horizontes, en una labor sistemática capaz de moldear a los individuos ${ }^{23}$. En este sentido, la sociedad igualitaria propugnada por Pardo de Andrade conserva un sabor autoritario muy dieciochesco, sobre todo en lo que se refiere al rescate de los desheredados. Del problema se había ocupado el escritor ya con anterioridad pero - por ser escalón previo en el acceso a la felicidad - lo vuelve a poner sobre el tapete en esta ocasión, abordándolo con un enfoque muy próximo todavía al de los reformadores ilustrados. Como en el caso de éstos, también aquí es evidente la atracción por soluciones compulsivas, que rebasan con mucho la simple concienciación educativa. La misma tendencia inspira el esbozo de reforma agraria del $n^{\circ} 40$, donde se proyecta el futuro del proletariado rural en función de intereses facilmente identificables con los de los propietarios acomodados, o, lo que es lo mismo, con los del capitalismo liberal de estricta observancia. Ese es el espíritu que preside la planificación de la agricultura allí propuesta, con su eliminación sistemática de los labradores sin tierras, incapaces de sobrevivir de manera autónoma y obstáculo insuperable para cualquier mejora técnica o productiva. A esa superpoblación de propietarios-jornaleros que afligía al Reino de Galicia - de hecho, pobres de solemnidad, dedicados la mayor parte del año al merodeo, como «langostas que todo lo consumen»se le habría de buscar aplicación útil en otra parte. Con la creación de fuentes de riqueza alternativas - las manufacturas, la pesca - habrían de ser absorbidos aquellos excedentes humanos, destinados en cualquier caso a formar el ejército de reserva del proletariado industrial. El escritor no se arredra ante las últimas consecuencias de su actitud sino que llega a sostener la emigración de artesanos y menestrales cuando tal medida se hiciera necesaria ${ }^{24}$. Una emigración, por supuesto, controlada y dirigida para que su fuerza-trabajo no se disolviera sin beneficio colectivo.

$\mathrm{Su}$ fe en la combinación de agricultura, industrias de transformación y tráfico comercial es ilimitada, con tal de que respondiera a un planteamiento racional y fuera monopolizada por la misma oligarquía que venía

\footnotetext{
23 "Cada uno de los ciudadanos tendrá trabajo en que emplearse y con el que poder ganar la vida honradamente; y los hombres pasivos, en virtud de la educación que recibirán y del infatigable zelo del gobierno por la felicidad pública se harán trabajadores y activos»: SPHLC, n 42 , p. 991.

${ }^{24}$ SPHLC, no 25, p. 579.
}

"CUADERNOS DE ESTUDIOS GALLEGOS", Tomo XLII, Fascículo 107, Santiago 1995. 
demostrando en el campo económico una notable competencia.Y, desde ese enfoque, por ser el «rico empresario» la única esperanza de modernización económica del país, su gestión e iniciativa se hacían acreedoras de la confianza pública. Se llega así a identificar el protagonista de la nueva sociedad, que no es sino el traficante de altos vuelos, emprendedor y arriesgado, el propietario acomodado, capacitado para hacer rentable la producción, cualquiera que fuese, ya agrícola o industrial. Son esos creadores de riqueza, capaces de hacer frente al arcaísmo de las instituciones locales, el objeto de la atención preferente del escritor, que les adjudica un papel directivo inequívoco.

\section{MENTALIDAD DEL PROVECHO Y APOLOGÍA DE LA LI- BERTAD}

No es difícil comprobar el mucho camino que había hecho esta mentalidad en la Galicia de comienzos del siglo XIX, y no sólo entre la población urbana. Dispersos en el aislamiento rural, hidalgos, curas de aldea y traficantes de toda laya aparecen ganados por la ideología del provecho y su comportamiento es la mejor demostración del partido que se podía sacar de la comercialización de la agricultura. Todos esos propietarios, especuladores en tierras y granos, importadores de lino y tejidos, traficantes y redistribuidores de mercancías, usureros, en fin, más o menos disfrazados de financieros, esto es, todos los que a la sombra de una larga era de libertades se habían enriquecido, ya fuera actuando en privado o monopolizando en provecho propio la reforma municipal carlotercista ${ }^{25}$, veían en la alianza con Francia su ruina. Para todos ellos esa línea política, que había prevalecido en los últimos tiempos provocando la paralización del tráfico marítimo y socavando la prosperidad anterior, requería revisión urgente.

Las consecuencias del descontento generalizado entre esas capas de población - que son, al fin y al cabo, operadores económicos de cierto relieve - se perfilan mejor considerando, además, el alto grado de penetra-

${ }^{25}$ Cfr. M.R. SAURIN DE LA IGLESIA, Reforma y reacción en la Galicia del siglo XVIII (1764-1798), La Voz de Galicia, La Coruña, 1983, pp. 126-129.

"CUADERNOS DE ESTUdIOS GALLEGOS", Tomo XLII, Fascículo 107, Santiago 1995. 
ción de la ideología revolucionaria en el país ${ }^{26}$ y su elaboración en vista de las particulares circunstancias españolas. Puede decirse que a principios del siglo XIX la percepción de las consecuencias de la Revolución había dejado de ser puramente negativa y esto explica la simpatía hacia sus grandes ideales. La conciencia de las ventajas de la libertad es por entonces profunda en los estratos sociales superiores y lleva a una postura selectiva que si condena el imperialismo de Napoleón admira en cambio otros muchos de sus logros. Así las cosas, interesa examinar los mecanismos del levantamiento popular contra los franceses siguiendo la perspectiva de estudio que apuntaba hace tiempo José María Jover ${ }^{27}$. Interpretarlo como «revolución inducida» resulta en este caso concreto muy sugerente ya que los sectores más progresistas eran precisamente los más perjudicados por la alianza con Francia y convenían en la urgencia de una reforma.

Son dos las etapas de la explosión revolucionaria, según las narraciones más conocidas de ella: en primer lugar la complaciente pasividad con que las autoridades del Reino, respetando los acuerdos diplomáticos, se entregan a los franceses. Y, a continuación, la «jacquerie» contra los invasores, desatada espontaneamente, según las historias al uso. Pero sin duda cabría deslindar entre el instintivo rechazo de la población ante las exacciones y violencias del enemigo - resistencia abocada al fracaso, como todas las formas primitivas de rebelión ${ }^{28}$ - y la compacta uniformidad que los grupos dirigentes supieron imprimir en toda España a esa protesta desorganizada. Incluso un conocedor superficial de la sociedad del Antiguo Régimen conoce la simbiosis que ligaba los colonos a sus señores y la facilidad con que éstos podían manipular su comportamiento. En este sentido es emblemático de lo acontecido en Galicia el comportamiento del Abad del Couto, por representar el eslabón que une la reelaboración del ideal de libertad por parte de las clases privilegiadas con el despecho de los estratos populares ${ }^{29}$. El mecanismo que se desencadena en éste y otros

26 "Les habitants de la Galice sont partisants des principes français plus qu'en aucun autre endroit de l'Espagne ...», hacían constar las autoridades del Directorio : v. Archives du Ministère des Affaires Etrangères, Paris, Mémoires et Documents. France, vol. 1967 , ff. 339 .

${ }^{27}$ Op. cit., pp. 182-208.

28 "... las insurrecciones que no fomentan los poderosos jamás son considerables ni temibles...», comentaba Pardo de Andrade a propósito de la situación en Francia: SPHLC, $\mathrm{n}^{\circ} 1, \mathrm{p} .7$.

${ }^{29} \mathrm{Cfr}$. Andrés MARTINEZ SALAZAR, De la guerra de la Independencia en Galicia, Ed. Galicia, Buenos Aires, 1953, p. 31.

"CUADERNOS DE ESTUdiOS GALlEGOS", Tomo XLII, Fascículo 107, Santiago 1995. 
casos parecidos, numerosísimos, es bien conocido y confirma una vez más el ascendiente incontrastado de la clase privilegiada en el ambiente rural; pero, de manera análoga, también la apasionada intervención de artesanos en el alzamiento coruñés evidencia su comunidad de intereses con la oligarquía urbana, motivo que lleva a menestrales y propietarios a hacer causa común. Todos ellos exhiben un acuerdo que supera los intereses particulares y parecen conscientes de lo que, en su más alto grado, llega a constituir una conciencia nacional. Para valorar esa sensibilidad patriótica sería necesario conocer mejor la actuación práctica de aquellos creadores de riqueza que eran tanto los industriales y navieros coruñeses como los hidalgos rurales. La crisis económica los afectaba a todos por igual. Y aunque en el caso de estos últimos sólo se conoce a grandes rasgos el movimiento de opinión que desde hacía medio siglo venía preparando su adhesión a la mentalidad del provecho, hay indicios evidentes de su disponibilidad como grupo para integrarse en un orden nuevo, al estilo inglés: en la coruñesa Academia de Agricultura había quedado trazada una línea de promoción agrícola capitalista aunque sin acabar de lograr por entonces la transformación de la tierra en mercancía. De manera análoga, también los experimentos e innovaciones practicadas por esos señores rurales en sus fincas de recreo o en sus casas solariegas denuncian a nivel individual la propensión a considerar la explotación del campo como un negocio susceptible de ampliación incesante ${ }^{30}$. En esa misma línea habría que inscribir los elogios de la nobleza comerciante de cierta literatura progresista local, desde Somoza de Monsoriú a Palomo y Torres. El predominio incontrastado en el interior del país de estos señores campesinos, partidarios de reorganizar las relaciones de producción y atraídos por la especulación económica, puede contribuir a explicar su alianza momentánea con la reacción emocional y la protesta del paisanaje.

Sin pretender establecer una relación mecánica entre la crisis económica de la fachada atlántica y las actitudes políticas de la población conviene considerar la aparición del «Semanario» como una etapa de la toma de conciencia burguesa. Con la creación de un órgano de opinión se intentaba dar cohesión y fuerza operativa a los grupos sociales que hacían de la productividad su propia existencia. Los valores por ellos sostenidos venían siendo considerados por Pardo de Andrade, ya desde sus primeras

${ }^{30}$ Cfr. M. R. SAURIN DE LA IGLESIA, Reforma y reacción..., cit., cap. I.

"CUADERNOS DE ESTUdios GALLEGOS", Tomo XLII, Fascículo 107, Santiago 1995. 
intervenciones en la prensa, en términos sumamente admirativos porque su triunfo llevaría a España a integrarse con pleno derecho en el mundo moderno; y, en cuanto fuente de bienestar para la colectividad, eran, por tanto, merecedores de apoyo. Con una terminología heredada del Siglo de las Luces, el escritor identifica como servicio a la patria cualquier contribución al crecimiento y mejora de la vida colectiva, ya se tratase de aumentar cosechas, criar ganado, producir aguardiente o tejidos. Según esta óptica, todo lo que condujese al desarrollo de riqueza debía ser considerado «desvelos de un buen patricio» así como «patriótico» era el apoyo a la colectividad partiendo del propio provecho ${ }^{31}$. La coyuntura bélica va a hacer deslizar el sentido de esta terminología hacía un campo semántico diferente, teñido de fuerte pasionalidad, en el que, sin embargo, seguirá siendo determinante la dependencia de la iniciativa individual con respecto a la utilidad colectiva:

«... para ser buen patriota y buen ciudadano es preciso que cada uno atienda la voz y propuestas del gobierno y que de su parte contribuya al buen éxito; el hacendado con sus facultades, el artesano con su trabajo y el negociante por medio de sus tráficos y especulaciones.... $\rangle^{32}$.

Fue precisamente el estallido de la guerra lo que dio un brusco giro al comportamiento de esos «patriotas», nutridos con la ideología de la libertad y decididos a reconstituir una nueva legitimidad que los favoreciese. Sin el menor propósito de subversión social pero obligado por el desmoronamiento del Antiguo Régimen a reorganizar el país, el grupo social más activo y responsable de él se apresta entonces a tomar medidas que le permitieran hacerse oír, precisamente en razón de ese patriotismo del que tantas muestras venía dando. El «Semanario» ofrece un panorama de las posibilidades de acción que la coyuntura ofrecía a todos los que participaban de aquella lógica. En primer lugar, en el elogio de la libertad que inaugura el periódico se destaca el valor de la propia individualidad nacional, cuya existencia histórica no debe ser avasallada y se justifica por sí misma. Pero esa personalidad, perfectamente diferenciada y dispuesta a

${ }^{31} \mathrm{Cfr}$. la frecuencia de esas expresiones en Artículos ..., cit., pp. 248, 254, 260, 265, $273,275,289$, etc.

${ }^{32}$ SPHLC, $n^{\circ} 35$, p. 824.

${ }^{33}$ SPHLC, n 24, p. 555; cfr. no 4, p. 75.

"CUADERnOS DE ESTUdiOS GALLEGOS", Tomo XLII, Fascículo 107, Santiago 1995. 
hacer respetar su peculiaridad ante el imperialismo francés, no es todavía tan sentida como sería necesario. Por eso uno de los cuidados principales del escritor es reforzar la idea de patria, débil en un país de particularismos tan fuertes como España. Corregir la ignorancia del vulgo en ese sentido significaba subsanar el aislamiento impuesto por la geografía peninsular y agravado por el atraso material que hacía de cada región natural un mundo incomunicado. Eso significaba superar tanto el cosmopolitismo típico de los privilegiados como el mezquino apego de los patanes a su rincón natal. La pasión patriótica que el escritor trata de inculcar en sus lectores debía servir como cemento de unión entre las gentes, unificando sus opiniones e incitándolas a grandes heroicidades. Por eso retrata la comunión de aspiraciones de los nacidos en el mismo suelo como una fuerza irresistible:

«...el patriotismo nace de la opinión que los hombres forman en pertenecer a una misma madre los que nacen en un suelo dividido

por la naturaleza de otro y de reputarse hermanos los que tienen una misma constitución civil y religiosa, y los que el uso quiso que perteneciesen a un estado, y llamó y apellidó con un mismo nombre»»33.

Imprescindible para vigorizar ese sentimiento se demostraba la libertad, amenazada ahora por los franceses. Y la estrecha correlación entre la idea de patria y la de libertad le brinda al escritor ocasión para desentrañar el sentido de este último concepto, al que los acontecimientos de la Revolución francesa habían acabado por identificar con el desenfreno. A esa interpretación se opondrá repetidamente Pardo de Andrade insistiendo en los aspectos positivos del término. De todos ellos le interesa en particular su equivalencia con el derecho de los individuos a condicionar el sesgo de los intereses colectivos, indicando metas tan atractivas como la consecución de una vida decorosa y digna. Y para recalcar la verdad de su tesis se servía del ejemplo inglés, demostración de un envidiable acuerdo entre gobierno y gobernados que valdría la pena conseguir para España ${ }^{34}$.

Los estrechos vínculos de esa idea de libertad con un programa concreto de gobierno dan lugar a multitud de consideraciones en todos los números del «Semanario». Así se va matizando poco a poco la concepción de aquella nueva entidad - la Patria - digna de ser defendida a sangre y

${ }^{34}$ SPHLC, no 3 , pp. 53-55.

"CUADERNOS DE ESTUDIOS GALLEGOS", Tomo XLII, Fascículo 107, Santiago 1995. 
fuego, al mismo tiempo que se libera su significado de la carga subversiva que la predilección de los revolucionarios franceses le había comunicado ${ }^{35}$. En lugar de aquellas adherencias peligrosas, lo que se subraya son los aspectos más sugestivos de un proyecto de vida colectiva asentado en un razonable bienestar para todos los grupos sociales:

«... la libertad por que peleáis y en que, logrado el triunfo, pondréis la nación, será la siguiente: tendréis un gobierno que, en vez de oprimir al pobre, no ha de pensar más que en su alivio y en proporcionarle medios de ganar la vida. Las mismas leyes han de sentenciar al rico que al pobre: No tendréis ni reconoceréis mas que un señor. Se os rebajarán los tributos, y no se pondrá ninguno sin que los pueblos lo concedan y consientan. Tendréis escuelạs en todos los distritos en que se enseñarán a vuestros hijos de balde las primeras letras. Asimismo tendréis médicos cirujanos que os asistan, y boticas. Podréis vender y comerciar libremente. No pagaréis luctuosas ni otras derechuras gravosas. Tendréis párrocos que sean vuestros verdaderos padres, y exemplares por su virtud. No tendréis guerras que no sean indispensables. El que gobierna la patria será el padre y no el opresor de los pueblos. Se establecerán y fomentarán la agricultura y las artes; y todo llegará a estar a precio tan moderado y equitativo que puedan el artesano y el labrador echar una gallina en su puchero cada domingo, vestir con decencia y vivir contentos $»^{36}$.

No es difícil imaginar la expectación con que serían acogidas tales proposiciones en una Galicia maltratada por la guerra y los abusos señoriales, ante la que se desplegaban como posibles e inminentes perspectivas jamás vislumbradas. El publicista no pretende lisonjear a su público sino que se limita a explicar el abecé de un bienestar que otros países disfrutaban ya y estaba a punto de realizarse en España. Cuando todas esas conquistas se hubieran materializado, el concepto de patria habría dejado de ser una abstracción retórica y la población entera estaría dispuesta a correr a su defensa porque

${ }^{35}$ Cfr. Norman HAMPSON, La Patrie, en The Political Culture of the French Revolution, vol.II de The French Revolution and the Creation of Modern Political Culture, Pergamon Press, Oxford, 1988, pp. 125-137.

\footnotetext{
${ }^{36}$ SPHLC, ${ }^{\circ} 36$ cit.
}

"CUADERNOS DE ESTUdiOS GALLEGOS", Tomo XLII, Fascículo 107, Santiago 1995. 
«en una nación libre el interés de la patria une y fraterniza al rey con los pueblos, los ricos con los pobres, los nobles con los artesanos y los plebeyos $»^{37}$.

El peligro de que este mensaje de libertad fuera mal entendido lo lleva, sin embargo, a subrayar la urgencia de que «la nación se ilustre», condición previa para cualquier reforma sólida.

\section{LA CONCIENCIACIÓN POLÍTICA COMO EDUCACIÓN PO- PULAR}

¿Cómo, sino, conducir al ejercicio de la soberanía a una sociedad acostumbrada al autoritarismo? Muy delicado aparecía el tránsito desde el Antiguo Régimen a la autodeterminación, cuando el tiempo apremiaba y unicamente recurriendo a la prensa cabía remediar el inmenso desconocimiento de cuestiones políticas de que adolecían los españoles. Sólo por su medio el pensamiento de las oligarquías renovadoras podía alcanzar a los demás estratos de población para constituir un movimiento de opinión compacto. Pero la actitud contradictoria de la Junta Central, indecisa entre la concesión plena o restringida de la libertad de expresión, había sembrado de incertidumbre el alcance de la prensa, retrasando además sus efectos. Pardo de Andrade lamenta esos titubeos que hacían perder un tiempo precioso para la concienciación general. Pero, al mismo tiempo, no deja de mostrar cierta perplejidad ante el torrente de noticias que, esparcidas de forma indiscriminada e insólita, pudieran contribuir al «trastorno de ideas». Lo que le preocupa, como a todos los escarmentados por el desbordamiento revolucionario francés, es no perder de vista la muchedumbre, controlar sus reacciones. De ahí su cuidadoso sopesar la responsabilidad de la prensa, de ahí su cautela ante las lecciones que pudieran desprenderse de ella, de que el público pudiera quizá tergiversarlas, por impericia en el uso de la libertad ${ }^{38}$. De ahí también la alta consideración que le merece la labor del periodista, el elogio de su discreción y mesura, destinadas a plasmar una conciencia cívica y a favorecer la eclosión de las virtudes patrióticas. Re-

\footnotetext{
${ }^{37}$ SPHLC, $\mathrm{n}^{\circ} 19$, p. 439.

${ }^{38}$ SPHLC, no 30 , p.704.
}

"CUADERNOS DE ESTUDIOS GALLEGOS", Tomo XLII, Fascículo 107, Santiago 1995. 
petidamente insistirá en la sensatez e integridad necesarias a los publicistas, obligados a ser «muy mirados y prudentes quando tratemos de ilustrar al público, evitando que éste se desmande, procurando insinuarle máximas de equidad, honradez y justicia» ${ }^{39}$.

Como telón de fondo de estas consideraciones se adivina el temor a promover involuntariamente un potencial de violencia irrefrenable.Y así, si en el «Semanario» está siempre presente la alabanza del pueblo y la apoteosis de la insurrección popular - furor legítimo por su objeto -, también destaca desde muy pronto la condena de la anarquía en cualquiera de sus formas. Brotes amenazadores de ella se habían dado en toda España con asesinatos y actos de vandalismo cometidos contra afrancesados auténticos o presuntos, en una sumaria administración de justicia que presagiaba consecuencias amenazadoras. La aparición de esa violencia criminal requería vigilancia para que las energías destructivas se canalizaran sólo contra el enemigo ${ }^{40}$. Pero, fiel a sus convicciones pacifistas, de ilustrado que acepta la guerra sólo como un mal menor, Pardo de Andrade evita incluso dar publicidad a acciones defensivas que no fuesen autenticamente ejemplares, es decir, que no sublimasen la simple ferocidad en actos de heroísmo. A pesar de esas reservas, el tono general del periódico es de franca admiración hacia la conducta seguida por el pueblo, que, a su entender, en Galicia se había demostrado excepcionalmente moderado en todos sus actos. La explicación de ese comportamiento se la ofrecen al redactor los principios del determinismo geográfico al uso, que le permitían atribuir el «genio dulce» y la «fibra blanda» de los gallegos a la templanza del clima, como acreditaba el testimonio de la Historia y la observación cotidiana se encargaba de remachar ${ }^{41}$. Ejemplo supremo de esa sensatez: el rechazo general de la supresión de cargas señoriales con que los franceses intentaban engolosinar a «un Reino dominado de feudos y señoríos $\gg\rangle^{42}$.

Pero el elogio del «pueblo» tiene todavía mayor alcance y profundidad y, si se observa la imprecisión que rodea este concepto, deja ver mejor sus

\footnotetext{
${ }^{39} \mathrm{Ibid}$.

${ }^{40}$ Ibid., $\mathrm{n}^{\circ}$ 26, pp. 603-604; cfr. Colin LUCAS, Revolutionary Violence, the People and the Terror, en The Terror, vol. 4 de The French Revolution and the Creation of Modern Political Culture, Pergamon Press, Oxford, 1994, pp.57-79.

${ }^{41}$ SPHLC, $n^{\circ} 4$, p. 75.

${ }^{42}$ SPHLC, n 15 , pp. 352-354.
}

"CUADERNOS DE ESTUdiOS GALLEGOS", Tomo XLII, Fascículo 107, Santiago 1995. 
ribetes políticos . Parece como si a Pardo de Andrade le interesara mantener aposta desdibujados sus límites para poder jugar con ventaja, ampliándolos o reduciéndolos según conviniera en estos primeros momentos de desconcierto en que no podía prescindirse de los privilegiados. Ganar la confianza de esos pilares del Antiguo Régimen significaba fortalecer las posibilidades de triunfo de los novadores, entre los que, por otra parte, ya se contaban muchos aristócratas. Y aunque en esta fase de su programa la alianza con la plebe todavía no aparece bien definida, poco a poco se va delineando con precisión el significado de ese «pueblo», protagonista de la Historia, suma de todas las fuerzas sociales y única fuente legítima de poder. Así, la idea del pacto social acaba por aflorar con claridad y la identificación liberal de Pardo de Andrade queda completa ${ }^{43}$. En su opinión, una primera expresión espontánea de esa voluntad general se había dado ya en la sublevación popular contra los franceses, actitud que contrastaba abiertamente con la de las autoridades. Se trataba ahora de hacer duraderos los frutos de esa primera insumisión de la plebe, con provecho colectivo. El escritor rechaza la interpretación que, ya desde la primera hora, hacía del clero el artífice de la sublevación porque, a decir verdad, los acontecimientos locales no permitían una interpretación optimista de la actuación conjunta del clero; otra cosa era su compromiso a nivel de individuos. Y, en su lugar, afirma el protagonismo popular como factor desencadenante ${ }^{44}$. La ambigüedad del término le permite, una vez más, ensanchar sus connotaciones para llegar, al fin, a adjudicarle al Tercer Estado todo el mérito y la iniciativa. Por otra parte basta hojear la parte histórica del «Semanario» para tropezarse a cada paso con el protagonismo de una clase dirigente que se adueña espontáneamente de la situación en los momentos culminantes y encauza a la masa amorfa de unos súbditos hechos a la obediencia. Es en esos «señores naturales» de cada comarca, en los propietarios acomodados y acostumbrados al mando, en quienes confía el escritor y a quienes asigna, de manera más o menos explícita, una misión directiva, según el estilo consagrado por el Antiguo Régimen ${ }^{45}$. Espera en su probidad y la considera promesa de una era de moralidad pública. Y escribe para dar a esa dirigencia ancestral una perspectiva po-

${ }^{43}$ SPHLC, $n^{\circ} 31$, p. 728.

${ }^{44}$ SPHLC, no 36 , pp. 844-846.

${ }^{45}$ Así, por ejemplo, en el nombramiento de caudillos: v. SPHLC, n 26, p. 606.

"CUADERNOS DE ESTUDIOS GALLEGOS", Tomo XLII, Fascículo 107, Santiago 1995. 
lítica unitaria no menos que para enriquecer los horizontes de una sociedad de enorme predominio rural, poco compacta y rudamente combatida en su evolución por resabios feudales.

Así pues, el «Semanario» sirve para homogeneizar los principios hasta allí tácitos que venían inspirando el comportamiento de esos grupos de poder, actúa como manual de urgencia o enciclopedia práctica de doctrinas ya conocidas, y es, en una palabra, la voz del liberalismo al alcance de todos. Para lograr su objetivo utiliza los medios que el Siglo de las Luces había puesto a disposición de los hombres de letras y muestra particular predilección por la poesía, a cuyo atractivo irresistible le encomienda una acción didáctica complementaria de la desempeñada por los ensayos doctrinales o por la sección histórica. Tanto es así que de las tres partes que componen cada número del «Semanario» una está dedicada a la creación literaria propiamente dicha. La razón de este predominio la da el mismo redactor cuando explica a sus lectores la urgencia de cultivar el espíritu para neutralizar de alguna manera el embrutecimiento inseparable de la guerra. Contraponer los delicados frutos de la cultura a la barbarie traída por las circunstancias forma parte del programa pedagógico que emprende el «Semanario» y cuyo lema bien podría ser enseñar deleitando. Con criterios típicamente ilustrados se le asigna a la poesía una función comunicativa de primer orden, de divulgación y persuasión al alcance de todos ${ }^{46}$.

La tarea es importante en un momento como aquél, en que los escritores más conocidos se habían pasado al enemigo y dejaban tras sí el vacío. Encabezándolos, los nombres popularísimos de colaboracionistas más o menos descubiertos, como Moratín y Meléndez Valdés, andaban en boca de todos y difundían sin querer un mensaje peligroso. Pues bien, para impedir que los admiradores de aquellos ídolos literarios se cegaran con su ejemplo, Pardo de Andrade se remite a otros modelos de bien decir que no son sino los suyos propios, arraigados como aquéllos en la tradición y, para más, apasionadamente patrióticos. Ese sentimiento - con las nuevas connotaciones que lo distinguen - inspira varias de las composiciones aparecidas en estas páginas, arraigadas en cuanto a la forma en la herencia más castiza y demostración además de que también la creación literaria

${ }^{46}$ Cfr. Joaquín ARCE, La poesía del Siglo ilustrado, Alhambra, Madrid, 1981, pp.214-222.

"CUADERNOS DE ESTUdiOS GALLEGOS", Tomo XLII, Fascículo 107, Santiago 1995. 
podía entenderse como un acto de patriotismo ${ }^{47}$. Así pues, con la libertad que el enfoque estético consiente y con una inspiración variada y fecunda, el «Semanario» echa mano no pocas veces de la poesía para abordar los problemas del momento en clave alternativa ${ }^{48}$. El dominio de la técnica poética que exhibe su redactor le permite tratar en varios tonos los temas más dispares: sin restar espacio al intimismo lírico, hay ocasiones en que un episodio de la antigüedad clásica sirve de parangón a los acontecimientos del presente, en otras predomina la idealización y consagración de los héroes de la guerra, alguna vez es el registro burlón el encargado de aliviar con la risa las tensiones del momento, y en muchas más parece como si el redactor, apremiado por el ritmo de la publicación, vaciara sus gavetas para salvar obras anteriores y desconocidas. La ocasión era de veras favorable para sacar del olvido una obra decorosa pero condenada a la oscuridad por las circunstancias personales del escritor. Sólo el desierto cultural provocado por la guerra y el disponer del «Semanario» dieron a Pardo de Andrade la ocasión para asumir el papel de restaurador de la poesía nacional, con todo el significado que eso conlleva.

El tono y la factura de todas estas composiciones revelan una sintonía con un público, cuyos gustos, asimilados en las aulas seguían impregnando luego la vida de todos los días, aunque fuese ya sin pretensión alguna de erudición. Cuando se conozca mejor el origen y formación de los negociantes afincados en La Coruña podrá reconstruirse el ambiente cultural de una ciudad en la que habría que sopesar también la fuerte presencia de magistrados y oficiales del ejército, creadores ya en tiempos del Cura de Fruime de una academia poética ${ }^{49}$. Determinante en la formación recibida por todos ellos en sus años de juventud había sido el viraje progresista y antiautoritario típico de la segunda mitad del siglo XVIII y que no podía dejar de impregnar todas las manifestaciones de la existencia. Reducir el alcance de la ética de la libertad que profesaba el elemento mercantil de La Coruña a sus actividades puramente profesionales es empobrecer la amplitud de las implicaciones ideológicas de esa postura, de las que la práctica del comercio no es, a fin de cuentas, sino la más visible. Por eso, en cual-

\footnotetext{
${ }^{47}$ SPHLC, $n^{\circ} 4$, pp. 90-91.

${ }^{48}$ Cfr. Manuel PARDO DE ANDRADE, Poesías, edición e introducción de M.R. Saurin de la Iglesia, Università degli Studi di Urbino, 1988, 2 vol.

${ }^{49} \mathrm{Cfr}$. Diego Antonio CERNADAS Y CASTRO, Obras en prosa y verso del Cura de Fruime, D. ..., Ibarra, Madrid, 1780, V, p. 321.
}

"CUADERNOS DE ESTUDIOS GALLEGOS", Tomo XLII, Fascículo 107, Santiago 1995. 
quier caso, aparece sumamente importante desentrañar el trasfondo cultural de esa burguesía local a la que pertenecían personajes tan curiosos como Juan Nepomuceno Ezcurdia, alumno de Jovellanos, o los diferentes miembros de la dinastía de los Urcullu, con sus inclinaciones literarias ${ }^{50}$.

Una primera formulación en términos estéticos de los valores prácticos que presidían la vida coruñesa se da ya en 1807. En esa fecha apareció el poema heroico Derrota de los ingleses en Buenos Aires, publicado por el Consulado «en obsequio de sus antiguos corresponsales y amigos, los valerosos habitantes» de aquella ciudad. Con esa obra, debida al mismo Pardo de Andrade, se pretendía exaltar los ideales que en las dos orillas del Atántico cooperaban al engrandecimiento de la burguesía. Muy à la page, los miembros del primer organismo económico del Reino se servían de la poesía culta y de la imprenta recién inaugurada en La Coruña para hacer la apoteosis poética de una epopeya burguesa. Exaltando la autodefensa de la población rioplatense contra la agresión británica realzaban un acontecimiento que les concernía muy de cerca, como que garantizaba los tráficos gallegos en aquellas tierras. Pues bien una función propagandística análoga es la que desempeña en el «Semanario» la poesía, vehículo de una ideología bien específica.

Ensalzando los episodios y personajes más sobresalientes de la guerra según las recetas de la mejor tradición poética castellana, se completa y resalta desde otro enfoque la información, que es el objeto explícito del periódico. Ese mismo planteamiento había inspirado ya anteriormente el «Diario de La Coruña», donde la inspiración patriótica era exclusiva, y volverá a repetirse en «El Ciudadano por la Constitución». Una mayor variedad de registros distingue, en cambio, las composiciones aparecidas en el «Semanario», no siempre puramente circunstanciales. Esa mayor amplitud de enfoque permite en él que la reflexión lírica se alterne con la exaltación de lo puramente ocasional de manera que, ya sea en alto estilo, con reelaboraciones heroicas a lo Tirteo, ya en versillos cantables destinados a los soldados, las glorias de la Patria se alternan eficazmente con otros temas. El encanto de la poesía es un estímulo más para el lector y por

\footnotetext{
${ }^{50}$ Juan Nepomuceno Ezcurdia, alumno del Instituto, es recomendado a Lord Vassall Holand: v. JOVELLANOS, Obras, B.A.E., Madrid, 1956, IV, pp. 468a. Sobre los Urcullu cfr. Vicente LLORENS, Liberales y románticos. Una emigración española en Inglaterra. 1823-1834, Castalia, Madrid, 1968, passim, y Jesús GUTIERREZ, Carlo Denina y su defensa de España, en «Dieciocho», nº 15, 1992, 1-2, pp. 1-17.
}

"CUADERNOS DE ESTUdIOS GALLEGOS", Tomo XLII, Fascículo 107, Santiago 1995. 
su medio se alcanza la ambiciosa meta que se había propuesto el redactor. Flexibilidad de inspiración y dominio de la expresividad confirman la regular fama de poeta que merecía Pardo de Andrade, cuyas repetidas intervenciones poéticas no desmerecen comparándolas con las de otros colaboradores — raras, en verdad - allí aparecidas.

También la sección histórica aborda con un espíritu característico la tarea de informar y educar a los lectores. Llama la atención, para empezar, el concepto de lo histórico que inspira al redactor, así como su atención preferente a los episodios locales de la resistencia antifrancesa. Esto deja entrever una peculiar asimilación de Voltaire y Montesquieu que le consiente trastrocar los términos de la historia al uso y dejar de remontarse a nuestro padre Adán para conceder plena dignidad al presente recién vivido. Ese enfoque le permite, por un lado, desatender las acciones de los soberanos para desplazar la atención desde el individuo a la colectividad, y dar voz a los propios protagonistas de sucesos verídicos y ejemplares, prestigiosos por eso mismo. Y, por el otro, le ofrece criterios tan insólitos para interpretar esa colectividad nacional como pueden ser sus condicionamientos naturales o sus costumbres ancestrales. En ese sentido resulta muy original el ensayito de «historia filosófica de Galicia» del $\mathrm{n}^{\circ}$ 15 , promesa de un inteligente acercamiento a lo local que Pardo de Andrade no llegó a profundizar. Pero cabría interpretar según esa misma línea varios ensayos de la parte política que explican con el recurso al pasado la renovación inminente. Esta visión dinámica de la Historia inspira, por ejemplo, los artículos acerca del valor y significado de las Cortes, organismo vivo, surgido en tiempos remotos de la necesidad colectiva y perfectamente idóneo para hacer reverdecer en el presente el buen gobierno de antaño. El escritor tiene gran empeño en hacer ver que restaurarlas no significaba imitar a Francia ni, menos todavía, resucitar antiguallas sin valor, ya que el protagonismo colectivo a que debían su originaria aparición tenía perfecta consonancia con el presente ${ }^{51}$. Nos sale así al paso toda una concepción de la historia de España fundada en la agrupación espontánea como instrumento de defensa común y expresión de libertad suprema ${ }^{52}$.

De manera aparentemente desordenada pero con tino y agilidad, el «Semanario» traza un cuadro riquísimo de la España en ciernes en 1809 vista

\footnotetext{
${ }^{51}$ SPHLC, no 16 y 17, pp. 361-368 y 385-393.

${ }^{52}$ SPHLC, ${ }^{\circ} 16$, p. 362.
}

"CUADERNOS DE ESTUDIOS GALLEGOS", Tomo XLII, Fascículo 107, Santiago 1995. 
desde la perspectiva de Galicia. Se van yuxtaponiendo así, con una gama de matices muy variada, temas a cuál más interesante: desde los cambios que la coyuntura prometía hasta sus consecuencias para el futuro; las reformas inmediatas que se requerían para llevar la guerra a buen fin; la crítica de las estructuras sociales y económicas; la denuncia de la inmoralidad pública; el elogio, en fin, de la nación, que acaba de descubrir su propia identidad y se transforma en protagonista de la Historia. Difícil tarea, en verdad, la del «escritor público» que así pretende convertirse en voz de la verdad y despertador de sus conciudadanos ${ }^{53}$. Para desempeñarla con acierto se requerían gran audacia y mayor convicción. Pronto se verían los riesgos entrañados por la postura de Pardo de Andrade. Porque, mientras unos lo ensalzan, otros tergiversan sus propuestas, y la franqueza con que se expresa le crea enemigos que no le perdonarán jamás sus críticas a lo establecido. Pero no será eso lo que descorazone al animoso redactor. Si un cierto descontento se trasluce cuando faltaba poco para cumplirse un año de la aparición del «Semanario», eso se debe más bien a la consideración de lo inadecuado de sus esfuerzos en comparación con lo conseguido. El balance de su acción individual no podía parecerle satisfactorio porque se estaba demostrando insuficiente para difundir en todas las capas sociales una efectiva conciencia política. Por eso, al comentar en el $\mathrm{n}^{\circ} 49$ la necesidad de salvar el abismo que separaba la población rural de las demás clases, encontramos una declaración de impotencia: la difusión de la conciencia política no era labor de un día ni de un individuo, tanto más cuanto la resistencia al cambio más temible venía de instituciones poderosísimas y perfectamente organizadas. Lo significativo es que en esta ocasión, al lado de pesadas acusaciones contra los «miserables egoístas» del estamento eclesiástico, aparece también la primera alusión al peso político del «rudo paisanage», urgentemente necesitado de orientación pero imposible de catequizar por los medios habituales. Las soluciones que el escritor sugiere entonces para acercarse a las masas se las inspira la importancia que empiezan a representar en su pensamiento como instrumento de equilibrio social $\mathrm{y}$, por muy ancien régime que parezcan, anuncian un giro importante en la consideración de los estratos ínfimos. Por eso, si de una parte sugiere la utilidad de una prensa oficial, instructiva y divulgativa a un tiempo - que parece recuerdo del «Semanario de Agricul-

${ }^{53}$ SPHLC, $n^{\circ} 29$, p. 679 y n ${ }^{\circ} 30$, pp. $700-704$.

"CUADERNOS DE ESTUdIOS GALLEGOS", Tomo XLII, Fascículo 107, Santiago 1995. 
tura y Artes dirigido a los párrocos» -, por otro las «fiestas y regocijos públicos, los himnos marciales, las comidas cívicas y otras útiles invenciones» - a imitación de lo practicado por los revolucionarios franceses- - le señalan un campo de acción al que se aplicaría en lo sucesivo. Iba a faltar el tiempo para llevar a cabo esa labor proselitista. Pero, aunque limitada, la conquista y catequización llevada a cabo por el «Semanario» debió tener sus éxitos pues el redactor se bañaba en agua de rosas al «ver cómo los artesanos se reúnen para comprar un exemplar y lo leen con el mayor gusto», prueba, a su entender, de las virtudes y patriotismo del pueblo bajo.

\section{DE LA ACCIÓN PATRIÓTICA A LA CONDENA COMO ENE- MIGO PÚBLICO}

Pero si el desamparo cultural de la inmensa mayoría se interponía como un obstáculo insuperable para la reforma, más insidioso aún aparecía, en el extremo opuesto de la escala social, el peligro entrañado por los «preciados de sabidos». Por eso el escritor recela de la ciudad «que debía ser la más instruida y patriótica», la refinada Santiago, que, sin desmentir su apego a lo establecido, dominada por su cabildo y Arzobispo, se aprestaba ya desde el primer momento a sostener a todo trance actitudes retrógradas ${ }^{54}$. El simple hecho de no contar más que con siete suscriptores en la capital cultural del Reino, y ésos, para más, simples particulares, es un síntoma poco halagüeño que entristece a Pardo de Andrade y le da motivo para deplorar la ignorancia en que se dejaba vegetar a la población. La abierta intención de dejar sobrevivir intactos «la rutina y usos antiguos»se podía observar ya en los decepcionantes resultados de las primeras elecciones, manipuladas por los eclesiásticos en los puntos más decisivos de Galicia. Y así, una vez evidenciados los fuertes intereses en contraste, no le era difícil vaticinar la guerra civil, pronta a estallar tan pronto como se hubiera apagado el fragor de la combatida contra Francia. A decir verdad, no era difícil tal profecía escribiendo en Galicia, uno de los Reinos con más supervivencias feudales y con más encarnizados defensores de ellas. Anticipándose ligeramente a Blanco White, que desde su observatorio

\footnotetext{
${ }^{54}$ Una expresiva semblanza del Arzobispo Múzquiz en TORENO, op. cit., p. 60a-b.
} 
londinense presagiaba un futuro desalentador ${ }^{55}$, el escritor de Jaz predecía ya en el $\mathrm{n}^{\circ} 17 \mathrm{del}$ «Semanario» «la división y acaso la guerra civil» desencadenada por «la diferencia de opiniones» 0 «por creerse perjudicada [...] una de las clases del Estado».

La tempestad de protestas desencadenada por los escritos del «Semanario» sobre la obligación cívica de contribuir todos por igual a las necesidades del Estado fue la primera señal de un endurecimiento de actitudes hasta allí no exteriorizado ${ }^{56}$. Precisamente el igualitarismo de esas reivindicaciones dio la señal de alarma, abriendo un abismo entre la postura liberal y la de los partidarios de la conservación del sistema. Pero si lo económico descubría de repente y con crudeza contrastes irreductibles, otros aspectos no menos amenazadores de lo establecido se podían entrever en el planteamiento de las tareas que el reformador pretendía asignarle a la Iglesia. Con una actitud que remite a lo mejor y más granado del cristianismo ilustrado, Pardo de Andrade definía desde el principio su pensamiento sobre la función de la institución eclesiástica en la sociedad. En un proceso creciente de racionalización, la reforma de costumbres es señalada como condición imprescindible para que el clero pudiera personificar dignamente el espíritu evangélico. Al mismo tiempo se le adjudicaba una misión benéfica exclusiva, desarrollada en el mundo «con el exemplo, la enseñanza y otros destinos piadosos». La exaltación de la figura del párroco, auténtico «padre de su pueblo» en cuanto socialmente útil, llevaba implícita la depreciación del clero regular. Cuando, por añadidura, se apuntaba como meta irrenunciable a la enajenación de sus riquezas en beneficio de la colectividad ¿qué más hacía falta para tocar a rebato? ${ }^{57}$. A partir de este momento el antiguo agustino se transforma en enemigo público de la poderosa Iglesia gallega, que no perderá ocasión de desprestigiarlo y, cuando llegue el ajuste de cuentas definitivo, de perderlo. Será precisamente en los periódicos absolutistas de Santiago donde se origine en los años inmediatamente siguientes una campaña de difamación perfectamente orquestada que, tan pronto como se cambiasen las tornas, culminaría en la condena a muerte del atrevido reformador.

${ }^{55}$ J.M. BLANCO WHITE, Dictamen sobre el modo de reunir las Cortes de España, en «El Español», 30.V.1817, p. 87.

${ }^{56}$ SPHLC, ${ }^{\text {o }} 18$, p. $415 ; \mathrm{n}^{\circ} 21$, p. 482 , y n 23 , p. 529.

${ }^{57}$ SPHLC, $\mathrm{n}^{\circ} 13$, pp. 290-291.

"CUADERNOS DE ESTUdIOS GALLEGOS", Tomo XLII, Fascículo 107, Santiago 1995. 
Por el momento, una vez convocadas las Cortes el escritor se siente relevado de su empeño y abandona la tarea. Había dado al público 51 números del «Semanario» con sustanciosas meditaciones sobre los problemas de un país en trance de resurgir de sus cenizas. ¿Hasta qué punto logró plasmar una conciencia pública? Sabemos que la tirada era de doscientos ejemplares ${ }^{58}$, cifra que no consiente ilusiones sobre el alcance real de su difusión y que confirma quiénes eran sus lectores, es decir, los convencidos de antemano, los acomodados «ilustrados» o el artesanado consciente, minorías sobre las que ninguna revolución puede ser construida. $\mathrm{La}$ esperanza de amalgamar sus fuerzas y de sumarlas a las de la población campesina - no muy decidida en el primer momento - pudo crecer y sostenerse en los tres años siguientes, durante los cuales Pardo de Andrade continuó su labor pero ya no a título individual. Para entonces La Coruña, transformada en refugio de liberales venidos de los puntos más conflictivos de la Península, dió impulso de manera sistemática a un auténtico programa de acción política en el que al escritor de Jaz le correspondió un papel de suma importancia. Actuando al lado de otros entusiastas reformadores, su radicalismo se fue acentuando a medida que se definía la importancia de los intereses en juego. La gran amenaza que la evolución de su actitud representaba para los intereses tradicionales se trasluce en los ataques de los adversarios absolutistas, que menudean a partir de ahí. Y como la toma de conciencia liberal sólo podía impedirse haciendo callar a los publicistas, he aquí que al regreso del deseado Fernando una despiadada persecución se desencadena contra ellos. Con una fuga dramática Pardo de Andrade se salva de la condena a muerte refugiándose en Inglaterra y recalando más tarde en Paris.

La condena alcanzó también sus escritos, que fueron incluidos por la Inquisición en una lista de obras prohibidas ${ }^{59}$. De esa manera, los ejemplares del «Semanario» poseídos por lectores y suscriptores se transformaron en un testimonio comprometedor del que procurarían deshacerse todos los que se habían distinguido por su progresismo. Así fue cómo desaparecieron de la circulación y son hoy una rareza bibliográfica de incalculable valor. La reedición facsimil actualmente en prensa pretende volver a poner el «Semanario» en manos del público para facilitarle el acceso a

\footnotetext{
${ }^{58}$ SPHLC, $n^{\circ} 49$, p. 1157.

${ }^{59}$ Archivo Histórico Nacional, Inquisición, leg. 4449, nº 12.
} 
una fuente primordial de nuestra historia que es, al mismo tiempo, el conjunto mejor trabado del pensamiento de su autor. A falta de otro retrato - que su escasa fortuna no debió permitirle jamás - allí queda reflejado un espíritu inquieto y generoso, que supo hacer vitales los ideales ilustrados en que se había formado, transmitiéndolos a la España dinámica de 1809. La imagen de lo que ésta hubiera podido ser, de no haber mediado la evolución que todos conocemos, se nos brinda como atractiva hipótesis de una línea de desarrollo que, entre otras cosas, le habría devuelto un puesto de primer orden en el concierto universal. 